\title{
Analytical prediction of tension force on stirrups in concrete beams longitudinally reinforced with CFRP bars
}

\author{
Rendy Thamrin ${ }^{1, *}$ \\ ${ }^{1}$ Civil Engineering Department, Engineering Faculty, Andalas University, 25163, Padang, Indonesia
}

\begin{abstract}
An analytical study to predict the tension force of stirrups in concrete beams that are longitudinally reinforced with Carbon Fibre Reinforced Polymers (CFRP) bars was carried out. Modified Compression Field Theory (MCFT) was applied in this study and a computer program was developed to facilitate the calculation process. The analytical results were compared with empirical formula and test data adopted from experimental study. Three concrete beams longitudinally reinforced with CFRP bars and transversely reinforced with steel bars were tested. Stirrups spacing was used as test variable. The beams were tested until failure and strains on the stirrups measured. The comparison between test results and the MCFT results shows that MCFT predicts the growth of tension force in stirrups well.
\end{abstract}

\section{Introduction}

In the last thirty years, the use of Fiber Reinforced Polymers (FRP) as a substitute for steel for longitudinal bars has become increasingly popular due to its high tensile strength and resistance to corrosion. Since the physical and mechanical properties of FRP bars are different from steel the resulting reinforced concrete structures will have different properties than their steel reinforced counterparts. A lower modulus of elasticity and nonplastic behavior can lead to higher deflection, wider crack width, and a more sudden brittle failure mode. The mechanical properties of FRP also affect the behavior of structural elements in response to shear forces. Therefore, research on shear force response behavior of the stirrups in FRP reinforced concrete beams is necessary.

Shear failure must be avoided in reinforced concrete structures. Shear failure occurs before the flexural capacity of the structural members is reached and leads to reduced structural ductility due to a sudden collapse. Due to this fact, a careful design procedure is needed so reinforced concrete members are able to withstand the shear forces. One of the analytical methods that can be used to predict the tensile stress in a stirrup is Modified Compression Field Theory (MCFT) [1]. This method uses equilibrium equations, compatibility, and stress-strain relationships to predict the relationship between shear forces and deformations.

\footnotetext{
* Corresponding author: rendythamrin@gmail.com
} 
A study related to the prediction of the tensile force on stirrups due to shear forces has been carried out by the author in the past $[2,3,4]$. An empirical formula to predict the tensile force acting on the stirrups was proposed [2]. In this study, MCFT is used to obtain a theoretical prediction of tensile force on the stirrups due to shear forces. Theoretical predictions based on MCFT were then compared to test data and the previously developed empirical formula.

\section{Analytical study}

\subsection{Modified compression field theory}

The calculation process for shear capacity of reinforced concrete beams using MCFT requires several parameters [5]; dimension of the beam cross-section, yield stress and modulus of elasticity of stirrups, yield stress and modulus of elasticity of longitudinal reinforcement, concrete strain value at peak stress, and concrete compression strength. In addition, the size and distance of the stirrup and the number of longitudinal reinforcements used are also taken into account.

The first calculation step is an estimate of the values of $\varepsilon_{1}$ (principle tensile strain) and $\theta$ (crack angle, as illustrated in Fig. 1). Then, the crack width, $w$, is calculated using these estimated values of $\varepsilon_{1}$ and $\theta$.

$$
w=\varepsilon_{1} s_{m \theta}
$$

where $s_{\mathrm{m} \theta}$ is the spacing of the inclined crack which depends on the crack control characteristics of the longitudinal reinforcement and stirrups [5]. This step is followed by an estimation of stirrup stress, $f_{\mathrm{v}}$, and application of the stress-strain law for cracked concrete in tension as shown in Fig2 to obtain the principal tensile stress, $f_{1}$.

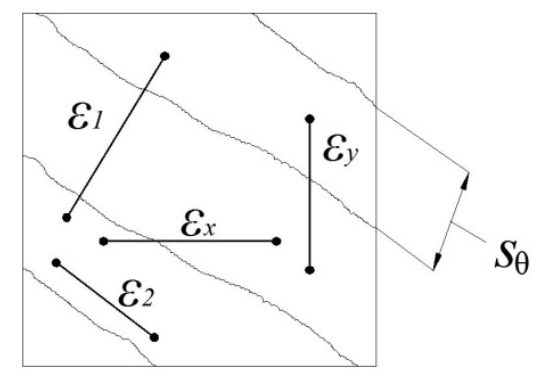

Fig. 1. Average strain in cracked concrete element [5].

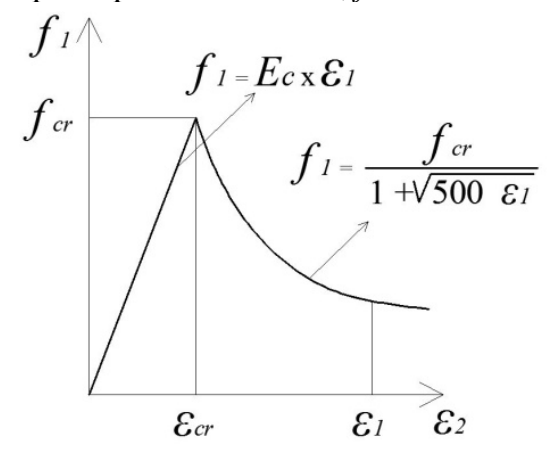

Fig. 2. Average stress-strain law for cracked concrete in tension [5].

The second step is calculation of the value of shear strength, $V$, of the beam using the distance between the stirrups, $s$, the area of stirrups, $A_{\mathrm{v}}$, and the stress on stirrups, $f_{\mathrm{v}}$. The shear resistance, $V$, of a reinforced concrete member as the total of a concrete and steel contribution can be calculated as

$$
V=f_{1} b_{w} j d \cot \theta+\frac{A_{v} f_{v}}{s} j d \cot \theta
$$

where $b_{w}$ is the web width, $j d$ is the distance between compression and tension reinforcement, $A_{v}$ is area of stirrups, $f_{v}$ is the average stress in the stirrups, and $s$ is the stirrup spacing. 
This second step is followed by calculation of the principal compressive stress, $f_{2}$, and the maximum compressive stress, $f_{2 \max }$. Figs. 3,4 and 5 illustrate the stress-strain curve of concrete, steel reinforcement, and CFRP bars used in this study. The maximum compressive stress, $f_{2 \max }$, is calculated using the following equation:

$$
f_{2 \max }=\frac{f c^{\prime}}{0.8-0.34\left(\frac{\varepsilon_{1}}{\varepsilon_{0}}\right)}
$$

where $f_{\mathrm{c}}$ ' is the concrete compressive strength and $\varepsilon_{0}$ is the concrete compressive strain at maximum compressive stress.

If the value of compressive stress is smaller than $f_{2 \max }$, the crack angle $\theta$ will increase. If the value of concrete compressive stress exceeds $f_{2 \max }$, then the process is followed by calculation of the concrete principle compressive strain, $\varepsilon_{2}$. After calculating the value of concrete principal compressive strain then the value of the stirrups strain (vertical strain) and concrete horizontal strain can be obtained.

The values of tensile strain of stirrups, $\varepsilon_{t}$, and tensile strain of longitudinal reinforcement, $\varepsilon_{x}$, can be calculated as [5]

$$
\begin{aligned}
\varepsilon_{t} & =\frac{\varepsilon_{1}+\left(\varepsilon_{2} \tan ^{2} \theta\right)}{1+\tan ^{2} \theta} \\
\varepsilon_{x} & =\frac{\varepsilon_{1} \tan ^{2} \theta+\varepsilon_{2}}{1+\tan ^{2} \theta}
\end{aligned}
$$

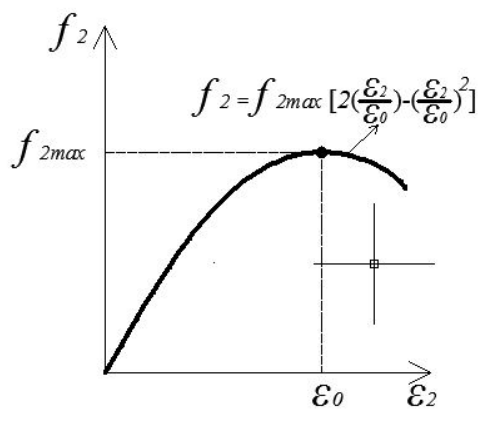

Fig. 3. Stress-strain law of concrete in compression [5].

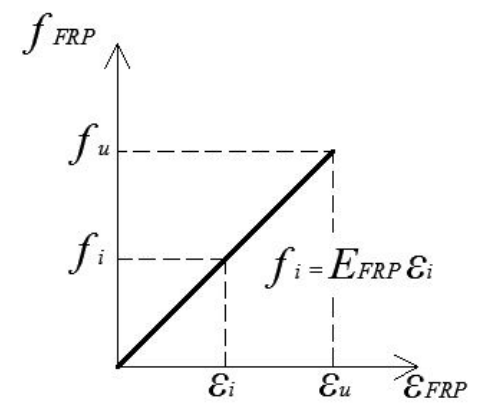

Fig. 5. Stress-strain law of CFRP reinforcement in tension.

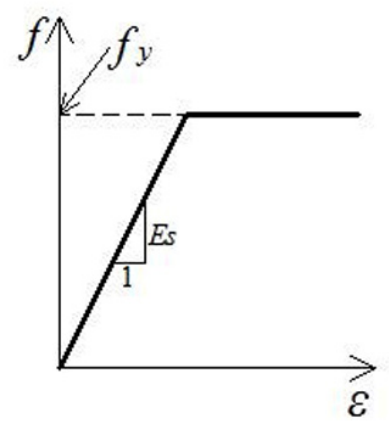

Fig. 4. Stress-strain law of steel reinforcement in tension.

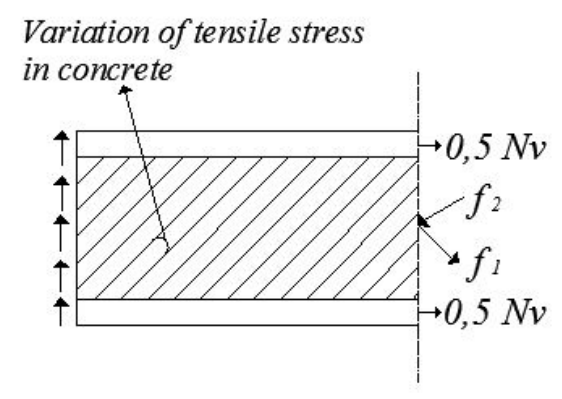

Fig. 6. Stress acting on a free body diagram of reinforced concrete member [5]. 
The iteration procedure needed to satisfy the equilibrium condition of the internal forces is illustrated in Fig. 6. If the total axial force, $N$, expressed in Eq. (6) is not equal to zero then the calculation process will be repeated with a new estimate for $\theta$.

$$
N=A_{s x} f_{s x}-\frac{V}{\tan \theta}+f_{1} b_{w} j d-f_{c}\left(A_{c}-b_{w} j d\right)
$$

where $A_{s x}$ is the web width, $f_{s x}$ is the distance between compression and tension reinforcement, $f_{1}$ is the average stress in the stirrups, $A_{v}$ is area of stirrups, and $s$ is the stirrup spacing.

\subsection{Empirical equation for tensile force on stirrups}

An empirical equation to calculate tensile force on stirrups has been developed previously [2]. This equation considers the parameters: stirrup ratio, $\rho_{s}$, number of stirrups along the shear span zone, $N_{s}$, shear force, $V$, and concrete shear capacity, $V_{c}$. It can be shown from the equation that the tensile force in stirrups increases significantly after the occurrence of diagonal shear crack represented by concrete shear strength, $V_{c}$. This equation is presented in Eq. (7).

$$
T_{s}=\left\{\begin{array}{cc}
0 & \text { if } V \leq V_{c} \\
\omega\left(V-V_{c}\right) & \text { if } V>V_{c}
\end{array}\right.
$$

where $\omega$ is the parameter for the tensile force equation of stirrups that can be calculated as

$$
\omega=2.5 / N_{s} \rho_{s}
$$

It is noted from Eq. (7) that $T_{s}$ equals zero if shear force smaller than $V_{c}$.

\section{Experimental study}

Three test beams (B-7, B-8, and B-9) from the author's previous work [2] were used in this study. These had dimensions of $130 \times 230 \times 1300 \mathrm{~mm}$. Stirrup ratios tested were $1.09 \%$, $0.72 \%$, and $0.48 \%$. Tensile force on stirrups was measured using strain gages (S1-S5) bonded to the stirrups (Fig. 7).

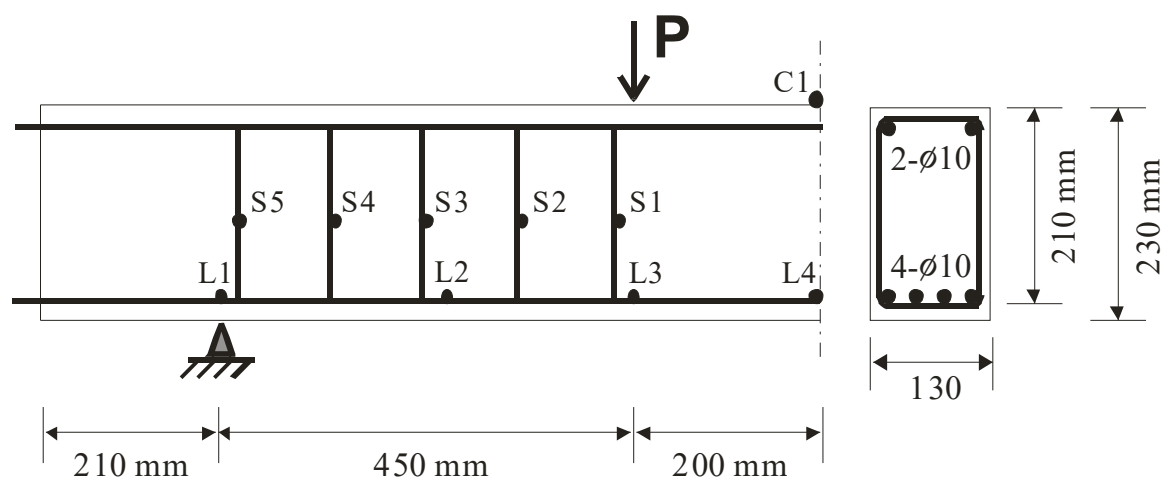

Fig. 7. Beam setup in experimental study. 
Deformed CFRP bars were used as longitudinal reinforcement (in tension) for all of the beams. The CFRP bars used contain about $60 \%$ carbon fiber. The compressive strength of concrete, $f c^{\prime}$, after 28 days of curing was $38.4 \mathrm{MPa}$. The tensile strength of CFRP bars, $f u$, was around $1800 \mathrm{MPa}$ and the modulus of elasticity, Ef, was $160 \mathrm{GPa}$. The longitudinal compression reinforcement was deformed steel bars with a diameter of $10 \mathrm{~mm}$, yield strength, $f y$, of $403 \mathrm{MPa}$, and a modulus of elasticity, Es, of $168 \mathrm{GPa}$. The type of the stirrups used was closed type with a diameter of $6 \mathrm{~mm}$ and yield strength, fys, of $823 \mathrm{MPa}$.

\section{Test results and discussion}

The predicted tensile forces of stirrups calculated using MCFT and Eq. (7) for each beam are plotted together with the measured test data (Fig. 8). The predicted values calculated using MCFT are represented by a bold dashed black line while the values determined from Eq. (7) are represented by a bold dashed red line.

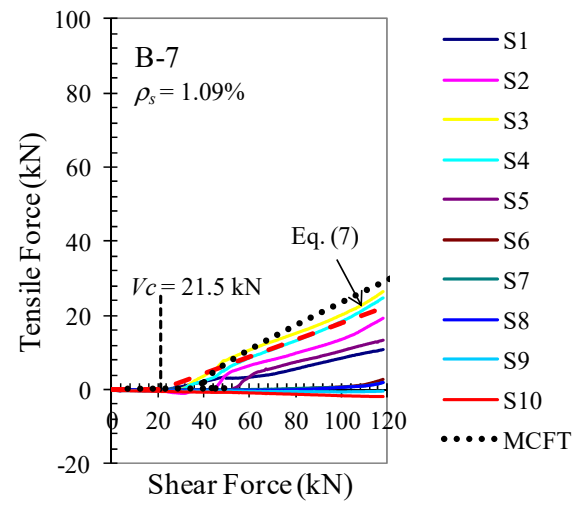

(a) B-7

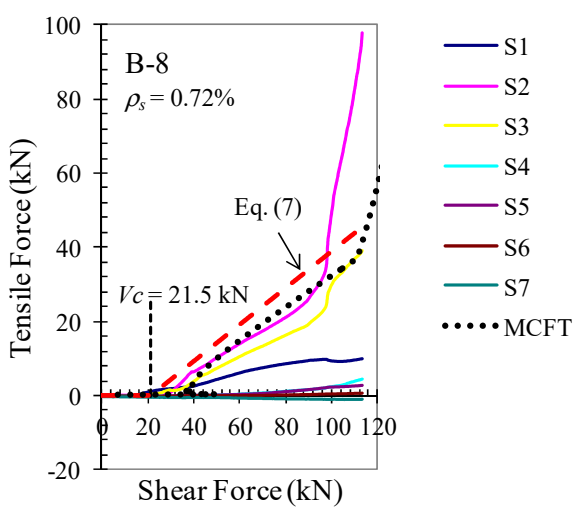

(b) B-8

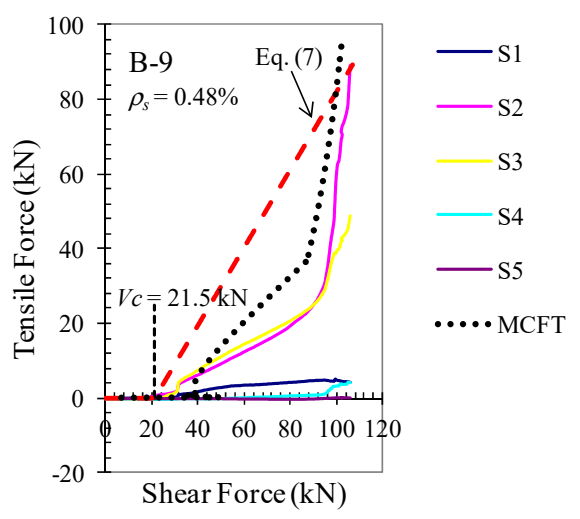

(c) B-9

Fig. 8. Comparison between MCFT, empirical equation and experimental data [2].

Fig. 8 shows that MCFT and Eq. (7) predict that the tensile forces on stirrups will significantly increase after the occurrence of diagonal shear crack in the shear span zone represented by $V_{c}$. This tendency has been documented in another experimental study as reported in [6]. Also Fig. 8 shows that MCFT predicts the growth of tensile force on stirrups well except for the beam with the $0.48 \%$ stirrups ratio. 
This deviation of measured results is also shown for predicted values calculated using Eq. (7). This result indicates that the accuracy of both MCFT and Eq. (7) in predicting the tensile force on stirrups strongly depends on the stirrups ratio in the shear span zone. This might be due to the high intensity of internal shear forces and bending forces acting simultaneously in the shear span zone of low stirrups ratio beams. However, both methods provide good estimates in the range of stirrup ratios commonly used in construction of structures. Fig. 8 also shows that the tensile force acting on stirrups in beams with higher stirrups ratio is smaller than the force in beams with lower stirrups ratio.

\section{Conclusions}

The test data from three concrete beams reinforced with CFRP bars were used to study the tensile force acting in the stirrups due to the shear forces and the accuracy of two prediction methods. The conclusions are as follows:

- Beams with a higher stirrup ratio have lower tensile force.

- MCFT and Eq. (7) predicted the growth of tensile force accurately on stirrups in case of beams with the higher stirrups ratio.

- The accuracy of MCFT and Eq. (7) in predicting the tensile force on stirrups strongly depends on the stirrups ratio in the shear span zone but both methods have high levels of accuracy for the stirrups ratios used in practical situations.

- In order to be able to predict the tensile force on stirrups in reinforced beams with low stirrups ratio, a new prediction model particularly for Eq. (7) must be developed to model tensile stress more accurately.

The author would like to thank the Engineering Faculty, Andalas University for the research fund support through Hibah Publikasi, Engineering Faculty, Andalas University with contract number 028/UN.16.09.D/PL/2018 in the financial year 2018.

\section{References}

1. F.J. Vecchio, and M.P. Collins, The modified compression field theory for reinforced concrete elements subjected to shear, ACI Journal, 83(2), 219-231, (1986)

2. R. Thamrin, Effect of end anchorage length and stirrup ratio on bond and shear capacity of concrete beams with non-metallic reinforcement, Journal of Engineering Science and Technology, 11(6), 768-787, (2016)

3. N.A.A. Hamid, A. Ibrahim, R. Thamrin, and H.A. Hamid, Experimental investigation on the shear behaviour of concrete beams reinforced with GFRP reinforcement bars, Advanced Material Research, 626, 559-563, (2013)

4. N.A.A. Hamid, R. Thamrin, A. Ibrahim, and H.A. Hamid, Strain distribution on reinforcement of concrete beams reinforced with glass fiber reinforced polymer (GFRP) bars, Key Engineering Material, 595, 812-817, (2014)

5. M.P. Collins, and D. Mitchell, Prestressed concrete structures, Prentice-Hall, USA, (1991)

6. S. Inoue, and N. Egawa, Flexural and shear behavior of reinforced concrete hollow beams under reversed cyclic loads, Proc. of 11th World Conference on Earthquake Engineering, Paper No. 1359, (1996) 